\title{
EL CAMBIO DE VALORES EN OCCIDENTE Y LA TAREA DEL PERSONALISMO COMUNITARIO
}

\author{
THE CHANGE OF VALUES IN THE WEST AND THE TASK OF \\ COMMUNITY PERSONALISM
}

Carlos Díaz Hernández*

\begin{abstract}
RESUMEN
El autor analiza las etapas de la crisis de valores en occidente considerando cuatro estadios: el teocéntrico, caracterizado por una fe ciega, teniendo como prototipo a Abraham; el teo-antropocéntrico, propio del renacimiento, la reforma y la ilustración; el antropocéntrico de Prometeo; y el pos-antropocéntrico y pos-teocéntrico de Narciso, en el que sólo queda el Yo, sin Dios a la vista y cuyos rasgos son: adiós a las cosmovisiones, el relativismo, el individualismo y el fin de la historia. Como salida de esta crisis se propone la visión del personalismo comunitario de E. Mounier, que concibe a la persona como un ser espiritual, como sujeto absoluto de valores, siendo ella un valor en sí mismo, vertebrado en tres ejes: el valor, el deber y la virtud. El personalismo comunitario es la contrapartida del capitalismo opresor y del individualismo abstracto.
\end{abstract}

\section{PALABRAS CLAVE:}

Teocentrismo, antropocentrismo, estadios axiológicos, nifilismo, humanismo, compromiso.

\begin{abstract}
The author analyzes the stages of the crisis of values considering four phases: the theocentric, characterized by blind faith, having as prototype to Abraham; the theo-anthropocentric, typical of the renaissance, the reformation and the enlightenment; the Promethean anthropocentrism; and the post- anthropocentric and post-theocentric of Narcissus, in which there is only the "I", without God at the sight and whose features are: goodbye to the worldviews, relativism, individualism and the end of history. As a way out of this crisis, the vision of community personalism by E. Mounier is proposed, that conceives the person as a spiritual being, as absolute subject of values, being a value in itself, divided into three axes: the value, the duty and the virtue. The community personalism is the counterpart of oppressive capitalism and abstract individualism.
\end{abstract}

\section{KEYWORDS:}

Theocentrism, anthropocentrism, axiological stages, nihilism, humanism, commitment.

* Docente de la Universidad Complutense de Madrid: carlosdiaz1@eresmas.net 


\section{ETAPAS DE LA CRISIS}

\subsection{Estadio teocéntrico: Abrahán}

La humanidad ha pasado por estadios axiológicos, con sus correspondientes crisis de transición. Casi hasta ayer ha vivido en el estadio religioso, cuyo prototipo es Abrahán, al que las grandes religiones monoteístas (judaísmo, cristianismo, islamismo) designan como patriarca: «Cayó Abram rostro en tierra, y Dios le habló así: 'Por mi parte he aquí mi alianza contigo: serás padre de una muchedumbre de pueblos. No te llamarás más Abram, sino que tu nombre será Abraham, pues padre de muchedumbre de pueblos te he constituido. Te haré fecundo sobremanera, te convertiré en pueblos, y reyes saldrán de ti. Y estableceré mi Alianza entre nosotros dos, y con tu descendencia después de ti, de generación en generación: una Alianza eterna, de ser yo el Dios tuyo y el de tu posteridad. Yo te daré a ti y a tu posteridad la tierra en que andas como peregrino, todo el país de Canaán, en posesión perpetua, y yo seré el Dios de los tuyos'. Dijo Dios a Abrahán: 'Guarda, pues, mi Alianza, tú y tu posteridad, de generación en generación. Esta es mi Alianza que habéis de guardar entre yo y vosotros -también tu posteridad-: todos vuestros varones serán circuncidados» (Gn 17,1 10). La respuesta de Abrahán al anuncio de Dios es incondicional: «Y Abrahán creyó en Yahvé» (Gn 15,6). Habla, pues, Señor, que tu siervo escucha, de ahora en adelante nada valdrá para tu siervo si se interpone a tu llamada, Dios mío. Desde el momento en que Tú el absoluto te has fijado en mí, tu siervo, yo ya no soy yo solo, eres Tú quien vive en mí.

A cada creyente Dios le dice: sal de tu tienda, sal de tu tierra, abandona lo que te adhiere a tu apego egocéntrico y te impide amarme, fíate totalmente de mí, aunque no entiendas del todo lo que pido si lees mi petición desde ti mismo; si la lees desde mi Amor y te fías incondicionalmente, entonces la considerarás como una ganancia. En fin, si el yo egocéntrico se pierde para Dios, y por ende para el propio yo, la entrega del yo a Dios es ganancia para Dios y para el yo mismo.

Ahora bien: ¿por qué habría de querer Dios trato conmigo?, ¿por qué necesitaría que yo perdiera mi yo?, ¿no podría Dios considerar mi yo como ganancia suya, sin que por eso fuese pérdida mía? A esta triple pregunta responde Dios con una triple respuesta. Primero: Yo, Dios, te he amado desde la eternidad en que te creé. Después: sólo podrás comprenderlo si sales de ti mismo, y me sigues, pues al verme me entenderás. Por último: aunque Yo te resulte incomprensible antes de quererme, cuando me hayas querido comprenderás que sólo ganarás aquello que seas capaz de regalarme, pues yo soy más íntimo para ti que tu propia intimidad. Fíate de mí, te amo intensamente y me tomo muy en serio tu amor amado; en él, por él, y con él encontrarás también tú mismo la fuente de todos tus amores.

Cuanto más cerca estés de tu propia tienda, tanto más lejos de Dios; cuanto más ligero de equipaje, tanto más cargado de eternidad. Tener dinero, o prestigio, o poder, en un bolsillo y a Dios en el otro no es religioso. El creyente da un salto, pero no hacia el vacío ni hacia la nada. Aquel monje trapense un día nos decía: orar es lo único que hago en mi vida día y noche; si Dios no existiera, yo estaría arrojando a los cerdos mi vida, pero he dado ese salto porque me fío enteramente de Dios. No son experiencias que se hacen un ratito. 
Dios es el generador de valores y la educación mira hacia el pasado en que Dios se reveló, hacia aquel tiempo en que todo «fue descubierto» por Dios para que se enseñase conforme a su palabra, en que todo lo que había que saber quedó perfectamente dicho para siempre. Dios habló, el maestro repite lo dicho por Dios, y el alumno repite ante el maestro lo por éste repetido. Convertido el maestro en catequista de lo eterno, el alumno asume esa enseñanza-doctrina (Sopeña, 1994). De ahí la aureola del maestro en cuanto que reactualizador del mensaje teocéntrico.

La memoria repite lo que Dios ha revelado, y la tradición ha entregado (traditio) de padres a hijos, generación tras generación. El padre es a la casa lo que el maestro a la escuela, con un patriarcalismo fuertemente normativo. El tiempo está como estancado, pasan siglos, se mantienen los valores vigentes, nada se innova, es más, cualquier reformulación o planteamiento crítico se considera una falta de reverencia, heterodoxia.

Por fin, la historia civil refleja la historia sagrada, por eso los modelos o arquetipos históricos a imitar son teocéntricos: Reyes Católicos, etc. Se comprende aún mejor este modelo, si lo contrastamos con el que en países como España irrumpe a renglón seguido, con un perfil antropocéntrico fuertemente contrario al teocéntrico.

\subsection{Estadio teo-antropocéntrico: Renacimiento, Reforma, Ilustración}

\subsubsection{Renacimiento, Galileo}

Galileo se encuentra en el Renacimiento con el problema ya previsto por los filósofos medievales: en caso de doble verdad (la verdad de la fe y la verdad de la razón) siempre hay que darle la razón a la fe. Ahora bien, a Galileo las matemáticas le dicen que la Tierra gira en torno al sol; pero la cultura religiosa de la época le obliga a decir lo contrario, a saber, que la Tierra no se mueve y es el centro del universo porque Jesús le ha elegido como planeta. Aquella manera de ver las cosas ¿cómo podría explicar que Cristo eligiera un pesebre para nacer?

Al final Galileo prefiere doblar la rodilla para morir dentro de la Iglesia, pues se retracta más o menos, a tenor de aquello que parece haber dicho mientras moría: «aunque no se mueva, sin embargo (la Tierra) se mueve». El Papa ha pedido perdón por ello en 1999.

\subsubsection{Reforma, Lutero}

Si Galileo quiere que la razón matemática y la fe sigan las mismas leyes, Lutero afirma que la capacidad de interpretar la Biblia es también la misma para todo ser humano, sea el Papa o el último laico, y cada creyente ha de arriesgarse a vivir la fe sin tutela alguna: es la libre interpretación o hermenéutica, «sacerdocio» universal sin prerrogativas especiales de nadie. Tanto Galileo como Lutero son creyentes, pero descubren que la razón (matemática o teológica) es adulta y que se puede leer la fe con la razón, ya que la fe sin la razón se infantiliza. Pero, si Galileo se queda en la Iglesia pese al conflicto, Lutero la abandona para fundar otra.

\subsubsection{Ilustración, Voltaire}

Voltaire da el último paso: del teísmo que adora a un Dios personal, al deísmo que invoca a un dios sin rostro, fuerza cósmica suprema que rige la 
naturaleza. Los masones veneran este orden cósmico en sus logias (logia: plural de Lógos, Razón), lugares de culto a la Razón universal. Cada masón refleja esa Razón en la suya propia interior, si es una persona de orden ético. Sólo más tarde la masonería irá perdiendo en religiosidad para ganar en poder. Esta humanidad adolescente, más antropo-teocéntrica que anti-teocéntrica, no es que no quiera a su madre la Iglesia, sino que le echa un pulso para medir su propio poder. La decapitación de Luis XVI en 1789 culmina con extrema violencia la tensión de este estadio: cuando su cabeza rueda y choca contra las piedras pulverizándose, cada ciudadano toma simbólicamente un trocito de esa cabeza, la pone sobre los propios hombros, y de este modo recupera su particular capacidad de pensar antes exclusiva del monarca (monarca $=$ uno solo es el que tiene el poder). El pueblo sustituye el monopolio del poder político-religioso de la corona por el poder popular. $\mathrm{O}$ al menos así lo cree.

\subsection{Estadio antropocéntrico de Prometeo (1789-1989)}

Tras este periodo breve pero intenso, a la generación de Abrahán le sigue la del titánico Prometeo. Generación revolucionaria, quiere hacer desaparecer a Dios de su horizonte, convencida de que el propio hombre será capaz de hacer el cielo en la Tierra. Cuando esto llegue en el futuro, los valores serán vividos con plenitud: así lo cree...

\section{Primero, el marxismo}

El revolucionario-superhombre instaura los valores que descubre como una afirmación de sí mismo: acabará con los inhumanos burgueses que dicen creer en Dios mientras expolian al hombre. Proletarios contra burgueses, hay que ganarse el título de humanos y los correspondientes derechos humanos, de los que por principio carece quien explota a los demás. Pero esa ganancia no se regala, antes al contrario exige la lucha de clases, movimiento de ruptura dramática. El movimiento obrero de los orígenes, de todos modos, no es ateo (Díaz, 1994), sino anticlerical, porque ve a la Iglesia aliarse con la burguesía.

\section{Luego, el nihilismo}

Para Federico Nietzsche no es la revolución obrera la que crea valores nuevos, sino el superhombre que cada cual descubre en sí mismo afirmando su voluntad de poder. Nietzsche sí rechazará la idea de que los valores humanos están sustentados en Dios.

\section{Finalmente, el psicoanálisis}

Por su parte Freud también critica la visión teocéntrica de la persona a imagen y semejanza de Dios, completando así el «magisterio de la sospecha» respecto del teocentrismo: Marx en el terreno social, Nietzsche en el ético, y Freud en el anímico. Contra Boecio, filósofo medieval, para quien el hombre es «sustancia individual de naturaleza racional», Freud afirma que ni somos racionales, ni sustancias individuales (estando en lucha el ello, el superyo y el yo), ni imagen de Dios. Según Freud, el ello, así llamado porque ninguno de nosotros lo quiere reconocer como suyo, es el impulso sexual, la pulsión básica, la energía libidinal que no puede ser juzgada con criterios morales, sino biológicos. El ello nos da vergüenza y nos autocensuramos por él, pero se nos aparece en sueños libidinosos. Freud reconstruye los sueños para recuperar esa libido y poderla administrar adecuadamente sin problemas éticos, no siendo el psicoanálisis sino el arte de administrar 
esa libido por razones de convivencia sin dejarse arrastrar por ella, pues quien no sabe frenar su libido se transforma en su esclavo.

El superyo es el yo que a cada cual le gustaría ser (el santo más bueno, la quinceañera más bonita, etc.). De carácter cultural, ideológico, en cuanto que arquetipo de perfección está construido por las exigencias paternas y sociales. El superyo es elástico porque según se alcanzan metas se va subiendo el listón, hasta que al final nos damos con él en la cabeza: «isoy tan estúpido, que no he sabido superar el listón!» Quien llega a ser ángel quiere ser arcángel. El arcángel serafín. El serafín querubín. El querubín potestad. La potestad dominación. La dominación trono. Y si llego a trono entonces quiero ser Dios.

Del ello me avergüenza su sexualismo animalizante, del superyo su idealidad excesiva. Aquél me impulsa hacia la tierra, éste hacia el cielo. Estoy dividido, en mi deseo de atender simultáneamente al ello y al superyo. Hay que buscar alguien que ponga orden en esta anarquía, y ese alguien es el yo. Sin yo, cabalgamos sobre dos caballos divergentes de difícil cabalgadura propensos a la esquizofrenia (esjizós, roto, partido). Hay que encontrar un yo capaz de manejar nuestra vida agarrando las bridas de ambos caballos armónicamente. Muchas gentes no lo logran: no todo el que dice «yo» es un yo. Dos consecuencias: primera, se pierde el carácter de un hombre imagen de Dios; segunda, la libido, más allá del bien y del mal, convierte al hombre en un animal amoral (a no confundir con inmoral: el inmoral es un moral malo, el amoral no tiene nada que ver con la moral, sólo con la biología). Freud exageró porque el amor está presente en la sexualidad y no es cierto que el ser humano sea amoral como un perro que no descubre más que la dimensión biológica, aunque por desgracia encontremos gentes que funcionan según el orden de los deseos caninos. Seremos polvo, sí, mas polvo enamorado.

\subsection{Estadio pos-antropocéntrico y pos-teocéntrico (pos-moderno) de Narciso (1989 en adelante)}

Pero la revolución comunista fracasó en su formato histórico (recuérdese que el Muro de Berlín comunista cae impotente en el 1989), y ya en el siglo XXI sólo queda Su Majestad el Yo, sin Dios a la vista, ni revolución social, ni valores objetivos. Es la posmodernidad, la era de Narciso, cuyos rasgos básicos serían:

\section{Adiós a las cosmovisiones}

«Simplificando al máximo, se tiene por posmoderna la incredulidad con respecto a los macrorrelatos. Esta es sin duda un efecto del progreso de las ciencias; pero este progreso, a su vez, la presupone. La función narrativa pierde sus functores, el gran héroe, los grandes peligros, y el gran propósito. Hay muchos juegos del lenguaje diferentes, es la heterogeneidad de los elementos. El criterio de legitimidad es tecnológico, no resulta pertinente para juzgar lo verdadero y lo justo» (Lyotard, 1984 p.10)

\section{Relativismo}

«A la moral de la convicción he contrapuesto la moral en constante tensión para refutar sus propios postulados y por verificar los del vecino. Paralelamente, a la moral cuyos criterios de valoración son la coherencia, la autenticidad, la autonomía y la realización ha de contraponerse la moral de la heteronomía, la incoherencia, la prodigalidad y la disolución personal: de la instrumentalización, de la dilapidación 
y del despilfarro de sí mismo. Según este criterio, bueno no es el acto que se dirige a mi realización, sino el que propicia mi disolución». (Rubert de Ventós, 1971, p.52)

«Cada maestrillo se pasea con su librillo» cuando todo se ha vuelto relativo, todo menos el yo, cada día más orondo. Es la era del collage. Sin modelos objetivos de magisterio, el alumno campa por sus respetos buscando la sabiduría en sí mismo convencido de su genialidad. En lugar de valores objetivos, meras metodologías formales potencian la subjetividad con bailes, cantos, juegos, y distracciones; poco más, fuera de la capacitación derivada de las habilidades profesionales.

En el ámbito familiar ocurre otro tanto, y los padres coexisten con los hijos en «plan de amigos». Si no se producen choques intrafamiliares es por la ausencia de convicciones. Mientras tanto, padres e hijos se dejan permear e indoctrinar igualmente por la omnipresente televisión, esa gran sembradora de normas a todas horas.

Por lo mismo decrece el monoteísmo de las religiones proféticas (de ahí la dificultad de la «nueva evangelización»), se ignoran la historia comunitaria de la salvación, el pecado, la omnipotencia amorosa de Dios, etc, en cuyo lugar se instauran sectas naturalistas, orientalistas y mánticas a la medida del consumidor.

\section{Pensamiento débil}

«Hay que pensar modelos desde el escepticismo y la desorientación que constituyen el aire que respiramos. Si es inútil buscar un Sentido unificador de la vida (no porque no se encuentre, sino porque será siempre la extrapolación de un sentido parcial), es porque hoy somos conscientes de la irremediable ambivalencia de nuestro mundo. Tal es el precio del pluralismo ideológico». (Camps, 1983, p.120) «No solamente un conocimiento débil, sino además un convencimiento débil» (Rubert de Ventós, 1984, p.54) en el imperio de lo efímero, del crepúsculo del deber y del sacrificio, de éticas indoloras sin sentimiento de culpa y sin propuestas fuertes. En realidad se trata de éticas de náufragos (Marina, 1994) para supervivientes en tiempos de crisis aguda, que rechazan mirar a lo lejos y que prefieren asirse a la primera tabla de salvación que encuentran, la del propio yo. Mas, si todo en nosotros es naufragio, entonces no podremos hacer otra cosa que desarrollar una cultura de supervivientes, no de herederos, pues nuestra continuidad genealógica y nuestros álbumes de fotos familiares han desaparecido cubiertos por el último golpe de las aguas que se llevaron el barco común al fondo de los abismos océanos. Ahora bien, la vida del superviviente resulta dura y poco envidiable, toda vez que ha de arreglarse con los restos del naufragio y se ve obligado a practicar una especie de canibalismo cultural; tiene a su disposición los restos de todas las culturas humanas a partir de las cuales elabora una identidad precaria, se fabrica un sentido consciente de su caducidad y fragmentación.

\section{Individualismo}

Paisaje con figuras individuales (ladrillos sueltos, náufragos) al fondo. Los individuos se retiran a sus espacios domésticos tras haber dado por perdida la batalla social, y se dedican mansamente al bricolaje sincrético como técnica de autoafirmación. A partir de este momento, quien demuestre que ha sido capaz de hacerse a sí mismo (self made man) se creerá facultado para deshacer a los demás. 
Ahora bien ¿se puede vivir real y verdaderamente en el aislamiento total? Más que vivir, sobrevivir cotidianamente (vivir sobre los otros) con asociaciones de egoístas, funcionales y pragmáticas. Los economistas posmodernos nos proponen una racionalidad moral basada en el egoísmo asociativo, una moral por conveniencia, una ética de los negocios, y a eso reducen el negocio de la ética; buena ética es hacer buenos negocios. Pocos recuerdan hoy aquella afirmación de John Stuart Mill: la fuerza social de una persona que tiene convicciones equivale a las de noventa y nueve que sólo tienen intereses. Gilles Lipovetsky, autor de libros muy vendidos en Europa tales como La Era del Vacío, El Imperio de lo Efímero, o El Crepúsculo del Deber (publicados en la Editorial Anagrama en 1986, 1990 y 1994) afirma: «Una persona 'buena' en el sentido de la moral del deber no siempre produce beneficios, por eso todos preferimos un gestor que robe un poco, pero que incremente la cuenta de resultados, a una bellísima persona que con su bondad nos lleve a la ruina. Los santos pueden ser perjudiciales para el bienestar general, mientras que los astutos pueden resultar beneficiosos. Al individuo responsable le interesarían más los segundos que los primeros».

\section{Fin de la historia}

«La única filosofía de la historia que aún podemos profesar tras el fin de la filosofía de la historia (o sea, tras el fin del mito del progreso, de la revolución, etc) es la que acepta como algo propio el final de la filosofía de la historias (Vattimo, 1986), Con ayuda del Estado de bienestar, el Imperio y sus satélites han alcanzado sus últimos objetivos. Ahora, a gozar hasta que el mundo se acabe. A los que queden fuera de esta historia ya concluida se les cierran las puertas: nuestro bien flanqueado y militarizado occidente no desea emigrantes con ganas de rehacer la historia.

Según el posmoderno ya hemos superado el viejo mundo de la injusticia y las religiones nada significan, y ahora a vivir que son dos días enfocando la cámara hacia el propio ombligo. Lo que era un muro se ha convertido en tantos muros como ciudadanos; decapitado el gran muro-dragón, de cada una de sus cabezas renovadas han surgido otras tantas murallas. La Hidra policéfala reproduce en cada una de ellas el pensamiento global, es decir, el hambre de 3/4 partes de la humanidad. La revolución fracasada no ha alcanzado el cielo, pero ha dejado tras de sí un archipiélago de infiernos. Estamos en el escalón más bajo del desarrollo moral (el egocentrismo), pero en el terreno de la propaganda en el más avanzado.

\section{VALOR, DEBER, VIRTUD: LA FUERZA DEL PERSONALISMO COMUNITARIO}

Tiene el ser humano tres vértices: el valor, que es la dimensión objetiva de la moralidad; el deber, que es la respuesta subjetiva a ese valor; y finalmente, si logro responder bien, obtengo la virtud. El resultado es un carácter moral. En efecto, el valor captado despierta en mí el sentimiento del deber; si ejerzo bien el deber, realizo una acción virtuosa. La virtud es un valor que se ha hecho vida en nosotros. La virtud es un hábito de excelencia o perfección. Siembra una acción y recogerás un hábito, siembra un hábito y recogerás un carácter, siembra un carácter y recogerás un destino.

\subsection{Autonomía y aristocracia del deber}

Resultan fatigantes los fardos del itú debes!, pues el gusto del querer se 
convierte en la exigencia del requerir. Animal modesto y desacreditado, el camello que los porta es el mejor en la travesía del desierto; sin embargo, nadie, y menos que nadie el abúlico, debería burlarse de su joroba, pues en ella conserva la humedad necesaria para la dura travesía que le posibilitará el magnífico regalo que ofrece al mundo: «Señor -exclamó Leonardo da Vinci- tú nos das dones, pero nos pides a cambio la fatiga». A diferencia del camello, la persona asume el fardo de su libre querer autónomo, dispuesta a dar la vida si fuere menester, a darla sin quitarla, a darla sin mentir ni escudarse en nada que no sea el mero darla, sin esperar recompensa alguna, sin dejarse llevar por los deseos alocados ni por las gratificaciones interesadas, sólo por puro sentimiento del deber, por el gozo del deber: cacaso no merece la pena una larga travesía, si con ella salvas cualquiera de los micromundos que laten en el mundo? Incluso aunque nada se lograse, merecería la pena volver a intentarlo.

Nada mejor para encauzar el esfuerzo humano que hacerlo brotar del deber, palabra vigorosa que asusta a tantos escolares, muchas veces abrumados por el exceso de unos deberes que castigan sus frágiles espaldas, sin que sepa nadie explicarles de verdad por qué ni para qué el deber de hacer los deberes...

Aristócrata moral es el sentimiento alegre del deber, plebeyo el sentimiento triste del derecho. Por eso:

El aristócrata moral siente que libertad y deber van juntos, pues sólo el libre puede asumir el deber de ser libre; el plebeyo ve en todo deber una forma de esclavitud, y en el mero derecho la única libertad.

El aristócrata moral reconoce: yo debo, y de lo que yo debo hacer soy el único responsable; el plebeyo masculla: mi yo sólo tiene derechos.
El aristócrata moral valora el papel del esfuerzo, del riesgo y de la aventura; el plebeyo se retranquea defendiendo al enano de sus temores.

El aristócrata moral asume la responsabilidad derivada de su acción; el plebeyo endosa al otro las responsabilidades propias, pero procura arrebatarle el fruto de su esfuerzo.

El aristócrata moral se regala incluso a sí mismo; el plebeyo está siempre a las maduras, pero nunca a las duras.

El aristócrata moral sabe agradecer, el plebeyo moral no entiende otra deuda que las deudas que a él le adeudan.

El aristócrata moral se encuentra en deuda iincluso por la gracia de amar a los otros!, el plebeyo reduce todos los rostros al suyo propio, porque ignora que sólo se posee lo que se entrega.

\section{QUERER EL DEBER}

\subsection{El amor al deber}

Ya hemos dicho que el deber no se impone al modo como a los niños del colegio los deberes. El deber se asume, se ama, se agradece, cuando a su vez se nos encarga por amor para amar más. En estas condiciones querer es querer deber, querer el deber; el deber aparece como una forma de querer, como un componente del cariño. Ese querer es virtuoso, de lo contrario sólo causa aflicción, fastidio, por ser de naturaleza burocrática. Por eso:

Haz todo el bien que puedas por todos los medios que puedas de todas las maneras que puedas en todos los sitios que puedas a todas las horas que puedas a toda la gente que puedas durante todo el tiempo que puedas. 
El cumplimiento del deber por amor es sapiencial, sabroso. Sin ese sabor de la sabiduría el esfuerzo es ciego, sin el esfuerzo esa sabiduría es impotente; si falta conocimiento no hay voluntad, sino instinto, pero si falta la voluntad el conocimiento es inútil. Como dijera Kant, nada hay tan bueno en el mundo como una buena voluntad: ¿de qué serviría saber mucho y ser muy querido, si no quisiéramos intentar hacer nada bueno? De bien poco: Yan-kieu dijo a Confucio: tu doctrina me complace, maestro, pero no me siento con fuerzas para practicarla. El maestro le contestó: los débiles emprenden el camino, pero se detienen a la mitad; tú, ni siquiera tienes voluntad para iniciar el camino; no es que no puedas, sino que no quieres. En la Parábola de Buda sobre la casa en llamas, Bertold Brecht trazó con gran maestría la imagen de lo que ha terminado siendo el final del siglo XX en Occidente: «No hace mucho vi una casa que ardía. Su techo era ya pasto de las llamas. Al acercarme advertí que aún había gente en su interior. Fui a la puerta y les grité que el techo estaba ardiendo, incitándoles a que salieran rápidamente. Pero aquella gente no parecía tener prisa. Uno me preguntó, mientras el fuego le chamuscaba las cejas, qué tiempo hacía fuera, si llovía, si no hacía viento, si existía otra casa y cosas parecidas. Sin responder volví a salir. Esta gente -pensétiene que arder antes de que acabe con sus preguntas».

No postulamos el hacer por el hacer, pero, en la medida en que se pueda, sin despreciar a quien no pueda, la acción será el fruto final de la madurez vital; sin voluntad de acción sólo queda pesimismo, declarado o encubierto: quien estime inmodificable una realidad no será sino un simple pesimista (a veces también un pesimista simple disfrazado de realista) respecto de ella, por mucho que brame en su contra. Hablamos aquí, obviamente, de una acción sabida, querida, debida, podida, esperada, orada, alabada, y no de la acción por la acción, no del mero activismo, pues lo que se hace sin formar una mentalidad carece de sentido. Mucho hablar y poco hacer no es de recibo, en absoluto. Abundan las historias de las problematizaciones, parálisis agitadoras donde el mucho hablar es un mero encerrarse en la banda de las aficiones eruditas, en la ilusión del Dato o en la ilusión del Lenguaje, que son a la par la fortaleza del Dato o la fortaleza del Lenguaje, donde prima el miedo a la libertad cuya prueba es la acción. Nosotros creemos en el compromiso de la acción. El acontecimiento será nuestro maestro interior.

\subsection{El deber como ejercitación del carácter moral}

Una voluntad que quiere ejerce su asertividad, lo contrario de deserción. La persona pusilánime, inhibida, hipersensible, no puede afirmarse en el mundo, algo pavoroso está a su acecho que puede caer encima de ella en cualquier momento, es hipocondríaca por vivir más atenta a sus propias dolencias reales o supuestas que a sus interlocutores. El 99\% de nuestras angustias son imaginarias, pero nadie lo cree así. La escala de Moss, que indica la dureza de los minerales, va desde el talco hasta el diamante. El talco es rayado por todos y el diamante raya a todos sin ser rayado por ninguno. Hay personas talco.

Tienes que elegir entre ser asertivo o no serlo. Si no eres asertivo te vienes abajo, vuelves contra ti los conflictos, sufres por sufrir, te refugias en la derrota, te dan ganas de largarte y caes en el conformismo. Es necesario reconocer que solos no podemos y que tenemos que pedir ayuda en diversos grados. 
Siempre se puede, al menos intentarlo: un problema es una oportunidad. Por miedo a la acción mucha gente se neurotiza y no hace nada. Por otra parte, nos ayudará a saber, a querer y a poder, quien nos quiera.

\subsection{El valor moral del coraje}

Puedes cuando tienes voluntad y reconoces tus errores; cuando no pierdes la alegría y anticipas la victoria; cuando te dejas querer por quien te quiere más. Es necesario aprender a afirmar (se), sin olvidar el sentido del prójimo. Y es la voluntad del sujeto que, dejándose querer bien, quiere bien a los demás la única que convierte a la fuerza meramente física en poder humano. El dinamismo de la voluntad no se entendería bien sin la categoría de pasión: pasión como singularidad apasionada, y pasión como padecimiento cuando choca con la resistencia del no-yo, con lo difícil. Para la hormiga el rocío es una inundación, ciertamente, pero no hay tampoco que echar en saco roto aquella afirmación de Montaigne: la dificultad da valor a las cosas. Si héroe no es sólo aquel a quien podemos elogiar en lo grande, sino también admirar en lo pequeño, entonces normalidad y heroísmo distan de ser incompatibles, según lo narra Julio Cortazar en la portentosa odisea del valiente que abandona una tarde su butaca, desciende la escalera, desafía el tráfico callejero, viaja hasta la esquina, adquiere el periódico y, de nuevo, navegando contra viento y marea, vuelve triunfalmente a su gran sillón. Lo que no puede faltar es el coraje. Coraje para vivir; generosidad para convivir; prudencia para sobrevivir; amor para desvivir: el coraje lo es siempre para las concreciones. Quienes hablan sin referirse a la realidad tienen un cadáver pudriéndoseles en la boca. El mundo es una montaña de mierda y hay que cogerla con las manos; lo importante es no ensuciarse el corazón.

Nosotros afirmamos el primado de una voluntad que es capaz de construir no sólo ideaciones (ideas), sino también idealidades (utopías), sin ceder por principio al poder de lo ya dado; es al buscar lo imposible cuando el hombre ha realizado siempre y reconocido lo posible, y quienes viven prudentemente limitados a lo que creen jamás avanzaron un paso. «iQué afortunado soy, exclamó el maestro! iCualquier falta que cometo es conocida inmediatamente por los hombres!».

\subsection{Un querer a la altura del deber}

Obviamente la presencia de la voluntad de ser más no anula el reconocimiento de una cierta jerarquía del desear, pues no deben confundirse el sano deseo y los insanos deseos. Desear muchas cosas no es lo mejor, pues no ha de ser el hombre a la medida de los deseos, sino los deseos a la medida del hombre. El mero antojo no es formativo; una cosa es desear apasionadamente teniendo a la voluntad dominadora como centro, y otra muy diferente desear muchas cosas, según la pulsión consumista donde la autarquía y la autonomía moral del sujeto se desvanecen, terminando por hacer a la voluntad misma esclava de los deseos, como los niños malcriados.

Las anorexias motivacionales estallan en el campo minado del relativismo moral, y últimamente vivimos tiempos de deseo casi prepersonal, sin voluntad, sin autocontrol, sin Deseo (escrito esta vez con letra mayúscula), que tienen al mero me apetece/no me apetece como único criterio. La universalización de tal arbitrio conduciría a admitir que aquel que más puede satisfacer su caprichosa apetencia sería el más valioso, de ahí 
que el desear sin el deber no valga, sino sólo un querer a la altura del deber. En caso de que desee pero no deba, mi deber será frenar el desear y aceptar el amargo deber; sólo cuando mi deseo y mi deber coinciden, puedo permitirme el gozo en toda su magnitud, sin sombra alguna de enfermizos remordimientos (el remordimiento sano es el deber contra lo in-debido).

\subsection{Da más fuerza sentirse amado que creerse fuerte}

El poder sigue al ser; él es fuerza, pujanza, eficacia, vigor. Pretender evitar el poder a toda costa resulta algo de todo punto imposible. Mientras hay vida hay también poder, en distinto grado; puede haberlo incluso hasta después de morir, como en la leyenda del Cid Campeador: poderosa es la memoria y la memoración que proviene de la evocación de los muertos. Aunque ciertas versiones de la ética al uso presenten al héroe poderoso como a un Rambo de musculatura correosa y aceitada, renuevo de aquellas del viejo Hércules, lo cierto es que hasta un enfermo total e impotente en su lecho goza de gran poder ante aquel que, por amarle, se lo confiere: ¿quién podría negar la importancia que en la vida de un padre amoroso ocupa un hijo necesitado en cualquier sentido? Es que el poder brota no sólo de las capacidades propias, sino de las fuerzas que nos confieren quienes nos aman.

Y esto, sin olvidar que el poder compartido es el único poder que puede. El poder podría poco si optase por incomunicarse. Puede más ese poder que va de poder a poder, a modo de sinergia de poderes, de interacción, de esa unión que hace la fuerza. No se trata de eludir el poder, sino de ejercerlo en justicia, y de impregnar a ésta de moralidad, en solidaria comunión con los demás, sistémicamente, participadamente, reticularmente. Son los actos de aquellos que sólo pueden pequeños gestos lo que contribuye a la creación de las grandes gestas. Son las microacciones las que posibilitan los grandes hábitos y las sinarquías finales en los individuos y en los pueblos. Y, si lo anterior es verdadero, entonces no lo es menos que el auténtico poder nunca brota de la coerción, ni del mero imperio dictatorial al modo de los poderosos de este mundo (de nuevo el plural fatal), pues -como afirmara Blas Pascal- la justicia sin la fuerza es impotente, la fuerza sin la justicia es tiránica.

\subsection{A lo imposible nadie está obligado}

Mas, si asumo un deber, he de intentar al menos saber hasta qué punto me considero capaz de ejercerlo, es decir, cuáles creo que son los límites de mi poder, cuestión tanto más importante cuanto más realista sea mi planteamiento al respecto, pues ċué sacaría yo en claro si sé, quiero y debo, pero me resulta imposible realizar ciertos deberes? Yo puedo hacer algo, pero no puedo hacerlo todo. A lo imposible nadie está obligado.

Así las cosas, puede ocurrir que mi voluntad quiera y pueda; quiera y no pueda; no quiera aunque pudiera; ni quiera ni pueda; iy hasta cabe que una parte de mí mismo se oponga a otra parte de mí mismo en su complejo querer-poder! El poder que no puede es la impotencia. Mas ¿qué hacemos con nuestras dolorosas impotencias? La impotencia es el querer que no puede. El impotente se siente incapaz, ineficaz, infructuoso, inerte, inútil, débil, infecundo, estéril, inválido, irrealizado... Aunque podemos mucho más de lo que creemos (el célebre ya no puedo más es cuestionable), sin embargo nuestro poder 
tiene límites, umbrales; fuera de Dios, nadie puede todo lo que quiere, por algo es viejo el apotegma veo lo que es mejor y lo apruebo, pero hago lo peor. A tan penosa realidad Aristóteles la denominó akrasía, y advierte que puede deberse a que el hombre incontinente abandona la elección, o a que abandona la conclusión a la que ha llegado; en el akratés falla el nexo lógico que liga el conocimiento de lo bueno y su realización voluntaria. Con frecuencia no sólo no hacemos lo que podríamos, sino que llevamos a cabo lo que no nos gusta; sabemos lo que podríamos, pero actuamos en sentido contrario. En el camino del no puedo, algunas de nuestras frustraciones más comunes son: no sé lo que puedo hacer, o lo que quiero hacer, o lo que debo hacer, estoy confuso y por tanto no puedo hacerlo; sé lo que quiero hacer pero no me atrevo; sé lo que quiero hacer y me atrevería pero no me merece la pena intentarlo; soy sinceramente incapaz de dominarme para hacer lo que quiero; quiero y puedo, pero no tengo quién me acompañe.

\section{LA FORJA DEL CARÁCTER}

Poco a poco hila la vieja el copo. Sin que nos demos cuenta, también con estos hilos va tejiéndose y destejiéndose el manto inconsútil de nuestra existencia, nuestro carácter axiológico, que no es el carácter psicológico que le sirve de soporte (más o menos avinagrado o risueño), sino la forma de estar en el mundo viviendo los valores y desarrollándonos como personas.

Existen dos formulaciones clásicas para expresar el modo en que se forja ese carácter axiológico. El imperativo pindárico de la voluntad, así llamado por haber sido formulado por Píndaro, reza: llega a ser lo que eres. Se trata de una invitación al desarrollo humano, pero también los animales llegan a ser lo que son. Más humanizador es el imperativo fichteano de la voluntad, debido al filósofo alemán Fichte, y que reza así: llega a ser quien puedes llegar a ser, el personal e irrepetible que llevas dentro y que merece ser perfeccionado. Uno se hace más humano si asume el deber de llegar a ser el que podría ser, mejor de lo que ya es, pues toda persona tiene la obligación de llegar a ser mejor, es humanógena, generadora de mayor humanidad individual y específica. Y, si además nos dejamos contagiar por quienes van por delante de nosotros en esa dirección, mucho mejor, ya que sólo llegamos a ser plenamente humanos cuando los demás nos contagian su humanidad a propósito, y con nuestra complicidad. La condición humana es en parte espontaneidad natural, pero también deliberación artificial: llegar a ser humano del todo es siempre un arte.

Los humanos no lo podemos todo, y por eso nuestro poder se tiñe -al menos parcialmente-de impotencia. Es la propia tarea que acometes, y la importancia que le concedes, lo que puede cubrir de gloria tus minutos, de lo contrario expuestos al fracaso. Pero hasta la misma impotencia de hoy puede convertirse en el poder de mañana, consistiendo toda la vida en la forja del carácter. La excelencia moral es resultado del hábito; nos volvemos justos realizando actos de justicia; templados, realizando actos de templanza; valientes, realizando actos de valentía, decía Aristóteles. Disciplina, perseverancia, orden, paciencia, humildad, todo eso son virtudes que ayudan a acrecentar el poder.

Se gana y se pierde en la forja del carácter, por eso quien para lo bueno no hace en su momento un poder siembra en el surco del mal que destruye la 
potencia («icómo subo, cómo subo, de pregonero a verdugo!»). Sólo quien trabaja bien puede crecer y hacer crecer. Al final, el mundo es un espejo, y a cada cual le devuelve la imagen de su propio rostro: frunce el ceño ante él, y te lanzará una mirada agria; trabaja por él, y él te ayudará a ti mismo. Nada más elástico y necesitado de habitud y de ejercitación que el músculo que mueve el poder. Hay que hacer un poder.

\subsection{Carácter: espera y esperanza}

El primer golpe de viento derriba mi casa, dejándome tan indefenso como al cerdito perezoso ante el lobo, si la des-esperanza y la des-esperación se meten en mi casa. Dante lee a la entrada del infierno el terrible abandonad toda esperanza los que aquí entréis, pues la vida se infernaliza para el des-esperado; por el contrario, mientras hay vida hay esperanza. Sin embargo, la muerte tiene tan segura su victoria, que nos deja toda la vida de ventaja; ella sólo teme la derrota procedente de otra vida más alta y capaz de borrar la muerte.

Paciencia y calma no se oponen a expectación ni a expectativa. El que espera está preparado para todo; no ve las cosas de color de rosa, ni se las promete demasiado felices, ni hace castillos en el aire, pero tampoco carece de ilusión, de optimismo, de algún grado de confianza: alberga, acaricia, alimenta esperanzas, por pequeñas que fueren. Es cierto que quien espera desespera, pero no lo es que quien desespera espere. La esperanza no es un cebo que nos pone el futuro para burlarse una vez más, ni una buena comida pero una mala cena, ni una lástima para quien vive de utopideces.

Quien sabe estar podrá ser, pues el modesto estar abre el camino al permanente ser, en el que se convierte con el curso del tiempo. El ser es un estar bañado en la permanencia cómplice del tiempo. Quien está ahí mucho tiempo termina siendo. Ocurre sin embargo que, por no dedicar tiempo a la causa, uno puede terminar perdiendo hasta la esperanza. En todo caso, el esperar se malograría sin la paciencia del mientras tanto. Adelante, hermano; deja que ciencia, arte y filosofía crezcan en ti tan íntimamente entrelazadas, que puedas parir algún día centauros.

\subsection{Carácter, veteranía}

Pero los enquistados poderes de este mundo se especializan en derrotar nuestra esperanza antes de que hayamos comenzado a ejercerla. Preguntado el senador Hubert Humphrey por la compasión en política tomó un largo lapicero, de ésos que tienen una pequeña goma de borrar en un extremo, y dijo: «Caballeros, fíjense en este lapicero. Del mismo modo que la goma de borrar no es más que una pequeña parte de todo el conjunto, y únicamente se emplea cuando se ha cometido una equivocación, así también sólo se recurre a la compasión cuando las cosas se le han ido a uno de la mano. La mayor parte de la vida es competición; sólo la goma de borrar es compasión. Resulta triste decirlo, caballeros, pero lo cierto es que, en la política, la compasión no es más que una parte de la competición». iY vas tú y dejas al senador horadar tus huesos para que deposite en ellos sus larvas; vas y crees al senador, porque, proporcionalmente hablando, la longitud de tu lapicero contrasta con la brevedad de tu goma! iQue así no sea! Además, ¿para qué esperas que tu goma borre parte de lo mucho que tu mina raya?, ¿no sería mejor si disminuyeses tu borrar, aminorando el rayar? Ánimo, aunque los demás no, tú si puedes: así que persevera contra las razones del senador. 
Parecería sin embargo que los amigos del senador se han especializado en extender su sábana fantasmal para ahuyentaros a cuantos de entre vosotros habéis asumido que ni sabéis, ni queréis, ni podéis, lo cual a ellos les sirve de coartada fenomenal para consolidar su victoria. De todos modos, Bertold Brecht viene siempre al encuentro de los valientes que resisten el asedio aunque a su alrededor los demás abandonen el barco a la deriva; amigo de los veteranos que permanecen, les recuerda: hay unos que duran un mes, buenos son, no los desprecies; otros duran un año, esos son mejores, felicítales; pero los imprescindibles son los que duran toda la vida. La veteranía es un grado para quien la trabaja; el veterano, aunque siempre en derrota, nunca en doma; la derrota suele ser pasajera, es la claudicación la que la vuelve permanente; él cuenta sus días por el número de sus fracasos, pero aunque sepa que va a fracasar se levanta al día siguiente más temprano: quien tiene esperanza se torna invencible.

Esperar significa estar ahí a las duras y a las maduras, lanzar las campanas al vuelo sólo a su debido tiempo, no llorar en mera previsión de derrota, perseverar: la perseverancia es ese trabajo duro que uno realiza cuando se cansa de hacer el trabajo duro que ya ha realizado, la permanencia en el tiempo después de que ha pasado el tiempo, por eso el tiempo del perseverante es tiempo estable, pase lo que pase, y por eso en él se establece y estabiliza. Cuando el que con per-se-verancia espera es inundado por una enorme alegría, no promete nada a nadie; cuando es dominado por un gran enfado, no contesta ninguna carta.

El envejecimiento físico vivido en esperanza es plenitud vital, aunque hoy «ser viejo y parecerlo, ser un viejo que asume el tiempo pasado, es algo casi obsceno que condena al pánico de la soledad y del abandono. A los viejos nadie les desea ya -ni erótica, ni laboralmente-, y la primera norma de la supervivencia social es mantenerse deseable».

\subsection{Carácter: saber continuar solo}

Veterano es quien -a falta de compañeros de relevo- se ve obligado a llevar la misma antorcha durante todo el trayecto, porque le han dejado solo. Desde la dura soledad del corredor de fondo, aunque veas a los demás en su particular maratón portando tan felices y contentos la luminaria de la basura a la que toman por rayo olímpico, aunque les veas progresar en el consumo de basura, tú sin embargo no afirmes nunca de ellos que son basura en progreso, pues tu carrera paralela no es para denostarles, sino para proyectar la luz de tu antorcha sobre ellos, a fin de que vean más claro y cambien el sentido de su marcha. Para eso estáis ahí, veteranas y veteranos del mundo. A la estirpe de quienes se saben quedar solos, incluso en un mundo de mutaciones y olvidos permanentes, inasimilables por su celeridad, pertenecen los esperanzados. Y si la realidad se obstina en borrar las firmes huellas de la esperanza bien visibles para el rastreador de largo alcance, pues peor para la realidad: debajo del asfalto se encuentra la playa. El veterano no se apea del milagro continuo, ¿jpor qué había de apearse, si la vida misma ya es un milagro a los ojos del militante esperanzado?, ¿para qué apearse, además, si cierta realidad resulta menos interesante que el principio esperanza? La esperanza es la más pequeña de las virtudes, la hermana menor, y sin embargo tan grande, que sólo por ella la dura espera se traduce en inabatible esperanza. No olvides aquélla anécdota: durante algún tiempo fue retirada la estatua de 
Montaigne sita en la Plaza de la Sorbona, frente a la Universidad. Alguien, sobre el pedestal vacío, aprovechó para escribir: Me avergüenzo de esta universidad, me voy. Sin embargo, a las pocas semanas, la estatua volvió a su sitio, remozada y reesperanzada. ¿El motivo? Se la habían llevado para repararla. Y, probablemente, a petición propia. ¿Moraleja? Te cansas, luego estás viejo, pero no le eches la culpa de tu cansancio al resto de los mortales.

Pocas cosas se obtienen por azar, pocos deseos se realizan por si solos. Hay que buscarlas con afán y alimentarlas con diligencia. La persona valiosa es la que se levanta después de una experiencia dolorosa, y no se consume en la inacción de la frustración. La prueba de la verdad es la acción. Siempre se puede hacer algo. La primera cosecha está ya en el hecho mismo de la siembra. Sembrar es ya cosechar. Al ir, irán llorando sembrando la semilla, al volver, volverán cantando recogiendo la cosecha. Nuestra vida es un trampolín no una hamaca. Obra de tal modo que no tengas que arrepentirte en aquella hora de haber hecho demasiado poco. Tu religión es lo que haces cuando termina el sermón.

\section{DE NADA SIRVE ENSEÑAR SI NO VIVES BAJO EL SIGNO DE LA VIRTUD QUE ENSEÑAS}

Cualquier enseñanza respecto de todo esto sería inútil si no nos enseñasen el vivir bajo el signo de la virtud, para qué queremos saber si no vamos a vivir lo que sabemos, nos quedaríamos a medias, porque lo verdaderamente importante es la vida. De nada sirve saber si no vives bajo el signo de lo que sabes. En muchas universidades lo que menos importa es que se viva lo que se aprende, es muy poca la gente que enseña para la vida. Pero no aprendemos para la escuela, sino para la vida. Por absurdo que parezca, así como la religión se pervierte a veces en rito sin alma, y como el matrimonio termina siendo en ocasiones rutina, también la enseñanza de la virtud puede acabar en expendiduría de diplomas y doctorados para gentes absolutamente de espaldas a lo que teorizan. Es señal de que hasta lo sagrado se profana, de ahí que hayamos de estar permanentemente en revisión si queremos evitar semejantes deslizamientos. En esto de los valores no hay más remedio que practicar la revolución permanente. No será escasa la suerte de quienes tengan maestros activos en esa dirección a los cuales tampoco les moleste que se les aplique a ellos mismos el cuento, y que además hasta lo agradezcan. Son, sin embargo, esas aves raras las que ennoblecen el vuelo.

Aristóteles define la virtud como el hábito de un padre de familia prudente que se sitúa entre dos extremos (justo medio); por ejemplo, la puntualidad no consiste en llegar ni temprano ni tarde, sino en punto, a la hora acordada; amar no consiste en querer tanto a alguien que lo asfixie, ni en estar muy alejado de él, sino en encontrar la distancia justa y adecuada, ni demasiado cerca ni demasiado lejos. Aristóteles pone como ejemplo al prudente padre de familia para mostrarnos que la ética debe vivirse todos los días y esto lo olvidan ciertos profesores de ética.

\section{NI EGOCENTRISMO, NI EXTRINSECISMO}

\subsection{Egocentrismo}

La virtud dista de dos defectos, el egocentrismo y el extrinsecismo. También las virtudes se corrompen, es decir, uno no gana una virtud para siempre; quien se declara poseedor de una virtud está encubriendo su egocentrismo, pues la 
virtud lo posee a uno y no a la inversa. Quien diga que posee el bien es un fatuo presuntuoso: «a un servidor a humilde no le gana nadie». Hay quienes dicen ejercitar sus virtudes y en realidad lo que desean es exhibirse, lo que menos les importa es la virtud. Sin embargo, esto es una forma pueril de egocentrismo, pues los que presumen de virtuosos son egocéntricos, dime de qué presumes y te diré de que careces. Si encaminamos nuestras acciones hacia un fin bueno y terminamos presumiendo de éstas, llegamos a un narcisismo egocéntrico o autotélico, donde uno hace de sí mismo el fin de la acción. Yo no puedo ir presumiendo de virtuoso porque automáticamente me convierto en autotélico, que es lo contrario a aristotélico, hablando ahora en el sentido etimológico de aristós, noble: lo noble es desarrollar la virtud.

\subsection{Extrinsecismo}

En el otro extremo de la virtud está el extrinsecismo. Quien para ser virtuoso exige premio o recompensa exterior («haré este acto bueno si me recompensas con otra cosa, de lo contrario no actuaré») es moralmente reprobable; asimismo, la acción virtuosa no está sometida al miedo al castigo («haré tal cosa o no la haré sólo para que no me castiguen»). Tampoco se es moral por actuar según lo mande la ley, sino únicamente legal; pero lo legal puede ser malo, ya que puede haber leyes malas cuyo acatamiento no tenga nada que ver con el ámbito de la moralidad, sino todo lo contrario, por muy legales que sean.

En conclusión, la persona tal y como es se manifiesta en la persona tal y como podría llegar a ser. Es decir, la virtud es la actualización de las bondades potenciales que hay en todo ser humano. Debemos buscar el desarrollo de la virtud y no del yo; el desarrollo del yo es fundamental, pero se da por añadidura a quien ama y practica la virtud. La tradición cristiana nos dice que la persona se plenifica si realiza el seguimiento de Cristo, fuente del deber ser.

No se puede vivir des-moralizado o a-moralizado. No existe ningún acto humano que sea amoral, sino virtuoso o vicioso. Una persona que abandona las responsabilidades familiares y se tiende en el campo porque no quiere trabajar comete un acto malo. Otra que se tiende en el campo después de trabajar por su prole comete un acto bueno. El primer descanso y el segundo son físicamente iguales, pero no lo son moralmente, porque el primero se halla inserto en una corriente de irresponsabilidad ética, a diferencia del segundo. Por tanto la vida humana desde el punto de vista de la moral, o es moral o es inmoral, pero no existe en ella lo indiferente. El valor moral del acto puede tener una intencionalidad distinta según la opción ad-optada. La persona a la que faltara la dimensión moral estaría des-moralizada o a-moralizada, es decir, desquiciada de su quicio vital, sin tono axiológico. En resumen, la ética busca la plenitud del ser humano, su tarea es la de forjar y fraguar un carácter o ethos. Acciónhábito-carácter-destino (destinación): uno termina recogiendo en su vida en buena medida lo que ha sembrado. Contando siempre con las posibilidades biológicas con las que llegamos al mundo, hay quien puede sembrar más y quien menos.

\section{SI SIEMBRAS UN ACTO TENDRÁS UN HÁBITO, SI SIEMBRAS UN HÁBITO TENDRÁS UN CARÁCTER, SI SIEMBRAS UN CARÁCTER TENDRÁS UN TEMPERAMENTO}

\subsection{La vida ética como proceso de ajustamiento}

Ética (de ethos) es el lugar donde uno vive, su morada, su primera naturaleza. 
Quien desde allí vive respetando su vida, su cuerpo y el de los demás, así como su entorno, conforme a lo que debe ser, convierte este «ethos» en ético. Si no lo hace así pasa a ser anti-ético, inmoral. Insistamos: el ser humano no puede ser a-moral, pero sí in-moral. A-moral es una piedra; in-moral lo es la persona que no se comporta conforme a lo que debe ser.

El ethos humano abarca una triple dimensión: naturaleza (physis), cuerporazón (lógos), convivencia (polis). El propio cuerpo y la propia razón se enmarcan en la naturaleza, nuestro cuerpo común. La convivencia social no consiste simplemente en ser vecino del otro a costa de los otros, no en que unos vivan y otros malvivan: la injusticia está contra la ética, es lo in-moral. Al equilibrio de estas tres dimensiones básicas le llamaban los griegos dyké (justicia), y al justo dykaios.

\subsection{Un ajustamiento temperado, no intemperante}

Por ser la ética forja de un carácter bueno, los latinos lo tradujeron como temperamentum, de temperare, templar: lugar donde se ejerce el temple. La persona de buen carácter tiene buen temple, la de mal carácter es destemplada, disarmónica, carente de humanidad virtuosa. La fragua de este buen carácter moral o temperatura ética es un proceso que se da a lo largo del tiempo, no algo que cae de momento o que pueda prescindir del tiempo. No por casualidad temperare viene de tempus, pues es en el tiempo, poco a poco, día a día, donde se va haciendo la identidad ética. Repitamos lo antedicho: si siembras un acto tendrás un hábito, si siembras un hábito tendrás un carácter, si siembras un carácter tendrás un temperamento, que es una forma de ser a través del tiempo. El temperamento es una siembra en el tiempo que forja un carácter, una forma de ser que se va enseñando o desenseñando, aprendiendo a aprender y a desaprender. Si aprendemos a desaprender lo bueno aprendemos lo malo; al aprender a desaprender lo malo aprendemos lo bueno. Mientras tanto no podremos presumir de haber ganado para siempre tal o cual hábito, porque vivimos éticamente como Penélope, que tejía por el día y destejía por las noches el mismo manto hasta que llegara Ulises, su esposo. Nuestro Ulises, nuestra Ítaca, nuestra patria de identidad axiológica no nos será dada desde luego antes de que nos llegue el último día.

\subsection{Un ajustamiento coeunte y transeunte}

En fin, que mientras vivamos seremos itinerantes temporeros, pero no viatores separados sino coeuntes, gente que camina junta. La ética la hacemos dentro de, en el interior de, y no separadamente de la physis, en el interior de la pólis, y todo ello desde nuestra propia identidad. Pero además de co-euntes somos trans-euntes, buscamos el más allá con los demás, la coeundia ética busca la transeundia de la felicidad, cada individuo va buscando el eterno sentido de su acción en la búsqueda de su otro yo y del nosotros, cuyo reencuentro le devolverá el tú eterno. La tarea ética: rescatar de la nada del olvido para una eternidad plena. Quien busca el yo contingente y se pierde en él mariposeando de tú en tú sin buscar el tú eterno, ése es un inmaduro, carece de carácter ético, mientras el que halla la otra mitad de su alma encuentra lo eterno en el «tú y yo» del nosotros, como don Miguel de Unamuno acariciando la pierna de su esposa y preguntándole con la ingenuidad de un niño: «Concha, cesta pierna es tuya o es mía?». En la obra de Italo Calvino, El vizconde demediado dos 
nobles disputan el amor de una dama, resultando uno de ellos cortado por la mitad por el tajo seco del sable enemigo. La novelita describe los avatares que acaecen a las dos mitades ya separadas, pero ni la buena puede vivir sin la mala, ni a la inversa, pues cada una de ellas echa de menos su alteridad perdida, hasta que al final se reencuentran ambas: odiando a la parte negativa de nosotros no lograremos reencontrarnos; sólo acogiendo con cariño nuestra disimetría, oscuridad y negatividad podremos algún día recuperarla.

Siempre heridos de separación y añoranza, ejercemos la búsqueda la coeundia de lo múltiple que hay en nosotros. Amar a otro (también a lo «otro» que habita en mí) es decirle: «Mientras yo viva, tú no has de morir». Que suerte tendrá aquella persona que crea que hay Quien le ama desde siempre y para siempre rescatándole de la nada del olvido porque, mientras viva ese Quien que nos ama desde siempre y para siempre, nosotros no moriremos.

\section{LA PERSONA, SUJETO ABSOLUTO DE VALORES}

\subsection{La persona, valor en sí mismo}

Esto es la vida moral: algo tan poético, y tan verdadero como esa herida de eternidad que lleva dentro el ser humano. Todos los valores son valores personales $\mathrm{y}$, si la persona que tiene esos valores no procura vivirlos valiosamente como tal persona en su totalidad, difícilmente podrá vivir ningún valor por separado y con independencia de ella; dicho de otro modo, la persona es sujeto absoluto de valores, y debe tratársela absolutamente conforme al valor máximo y radical que es. Como es bien sabido, Kant distinguía entre dos tipos de seres: aquellos que tienen valor en sí mismos, y aquellos que por el contrario sólo valen para otra cosa distinta de ellos mismos. Por ejemplo: un martillo, que es útil para clavar un clavo, pierde su utilidad cuando se rompe, y entonces su precio baja o cae totalmente. Sin embargo una persona humana es valiosa en sí misma, tiene valor siempre aunque ya esté rota o vieja, o aunque todavía no haya nacido, vale desde el primer instante y para siempre, es valiosa en sí misma y por eso no tiene precio sino dignidad, no es objeto, sino sujeto, y por tanto tiene valor y no precio. Como tal, sujeto nunca objeto, nadie esta legitimado para causarle ningún daño ni físico ni moral.

\subsection{La persona, fin valioso en sí mismo}

Según Emmanuel Mounier «una persona es un ser espiritual constituido como tal por una forma de subsistencia y de independencia en su ser; mantiene esa subsistencia e independencia mediante su adhesión a una jerarquía de valores libremente adoptados, asimilados y vividos en un compromiso responsable y en una constante conversión; unifica así toda su actividad en la libertad y desarrolla por añadidura, a impulsos de actos creadores, la singularidad de su vocación». No se trata de una definición en sentido estricto, pues definir implica poner límites objetivos a quien es sujeto. Tampoco puede ser captada por todos, ya que existen gentes ciegas para las personas como las hay ciegas para la pintura, con la diferencia de que muchos ciegos para las personas son responsables, en cierta forma, de su ceguera y llegan a serlo porque quieren una libertad mal ejercida. La vida personal es una conquista ofrecida a todos, algo que los animales no pueden captar y que las personas tampoco a veces, si no viven por encima de cierto nivel de animalidad. Mounier se refiere a la persona como un ser espiritual, pues tenemos una vocación de eternidad, queremos 
perseverar, que no nos olviden como queda olvidada al borde del camino una flor marchita. Esta espiritualidad tiene dos caracteres: subsistencia e independencia. Subsistimos, somos quienes somos porque vivimos adheridos a una escala de valores libremente adoptada. Si no nos adhiriésemos en libertad, no seríamos lo que somos (realidades espirituales). Esa adhesión a la jerarquía de valores la vivimos en un compromiso responsable con los demás: terminamos siendo lo que hacemos o dejamos de hacer. Por eso, aunque para hacer o dejar de hacer hay que ser, debería hablarse no sólo de naturaleza humana, sino también de condición humana.

El compromiso es una vivencia comunitaria (con), en favor de un mundo nuevo (pro), hacia el que nos sentimos enviados (missio), y sólo es responsable cuando la palabra se convierte en respuesta, y ésta a su vez únicamente cuando se traduce en responsabilidad por el otro. No es palabra si no responde a las exigencias reales, y no meramente verbales, de otra persona, de un tú, pues la palabra no es monológica, sino dialógica. Yo soy responsable de todo y de todos, y yo más que nadie en lo que yo tengo que hacer. Si opto por delegar en otro lo que me toca, sin ejercer lo que yo tengo que ejercer, elijo una vida impersonal. Las palabras que no son respuesta y la respuesta que no es responsabilidad no es palabra humana, sino mera palabrería.

Esta responsabilidad no es libre para elegir entre la peste y el cólera, sino vivida de forma responsable y en constante conversión. Recordemos que hay dos tipos de personas: los «divertidos» que hacen mil cosas distintas y que vierten a distintas laderas, hablando por acá pero haciendo por allá, y los convertidos, aquellos que se miden por su capacidad de concentrarse en la respuesta en una vida personal donde palabra y acción van unidas por el respeto a uno mismo, pues yo no podría dar respuesta a otro si no me cuidase a mi mismo, porque nadie da lo que no tiene. Al hacerme respuesta para otro me convierto en un mismo movimiento intencional en respuesta intencional para mí, unificando así toda mi actividad en libertad y desarrollando a impulsos de actos creadores la singularidad de mi vocación.

\subsection{La persona, pese a que a veces no lo merezca, siempre más digna de admiración que de desprecio}

Hay en cada persona más cosas dignas de admiración que de desprecio, porque a pesar de su conducta indigna de hoy puede mañana cambiar. Y no sólo por eso, sino -aunque se empeñe en lo contrario- porque el indigno vale más que las indignidades que él mismo lleva cabo. Más aún, porque quien le ama le rescata de su indignidad, aunque él no lo merezca. En fin, en lo eterno humano -en su naturaleza, en su ley natural- está escrito que: El ser vale más que el tener. Quien más regala es quien más posee, y hay más alegría en regalar que en retener. El dinero es necesario, pero insuficiente. Somos capaces de amistad, de preocuparnos por el otro, así irrepetible para nosotros. El amor es más fuerte que el odio. A todos nos gusta que nos quieran y nos traten como a personas. Da más fuerza sentirse amado que creerse fuerte. No somos medio o instrumento para el egoísmo ajeno, sino fines en sí.

\subsection{Personalismo comunitario}

Esta es nuestra jerarquía de valores: primacía, sobre todos los demás, de esos valores accesibles en la alegría, en el sufrimiento, en el amor de cada día, valores de amor, de bondad, de caridad. Esta escala dependerá intrínsecamente, para algunos de entre nosotros, de la existencia 
de un Dios trascendente y de unos valores cristianos, sin que otros compañeros la consideren como cerrada por arriba. La libre elección es condición previa a una adhesión sincera a estos valores, destinadas a vivir en una comunidad total. El capitalismo nos propone una sociedad opresiva sin verdadera comunión. El individualismo abstracto es una caricatura de la persona. Contra estas dos corrupciones reencontraremos las fuentes profundas instaurando el régimen personalista y comunitario.

\section{REFERENCIAS:}

CAMPS, V. (1983) La imaginación ética. Barcelona: Seix Barral.

DIAZ, C. (1994) España canto y llanto. Historia del movimiento obrero con la Iglesia al fondo. Madrid: ACC
LYOTARD, J. F. (1984). La condición posmoderna. Madrid: Cátedra

LYOTARD, J. F. (1986). La posmodernidad explicada a los niños. Barcelona: Gedisa

MARINA, J. A. (1994). Ética para náufragos. Barcelona: Anagrama

RUBERT DE VENTOS, X. (1984) Filosofía y/o política. Barcelona: Península.

RUBERT DE VENTOS, X. (1971) Moral y nueva cultura. Madrid: Alianza.

SOPEÑA, A. (1994) El Florido pensil. Memorias de la escuela nacional católica. Barcelona: Ed. Crítica.

VATTIMO, G. (1986) "El final del sentido emancipador de la historia". En «El País», 6/12/1986. 